\title{
CONSTRUÇÃO DE CAIXAS ENTOMOLÓGICAS COMO FERRAMENTA AO ENSINO- APRENDIZAGEM EM CURSOS TÉCNICOS DE AGRÁRIAS
}

\author{
M. O. GUIMARÃES-BRASIL ${ }^{1 *}$, F. A. L. SALES ${ }^{2}$, E. A. SOUZA ${ }^{3}$, C. E. F. CRUZ ${ }^{1}$, D. F. BRASIL ${ }^{3}$ \\ ${ }^{1}$ Instituto Federal do Rio Grande de Norte \\ ${ }^{2}$ Instituto Centro de Ensino Tecnológico \\ ${ }^{3}$ Universidade Federal Rural do Semi-Árido \\ michelle.guimaraes@ifrn.edu.br ${ }^{*}$
}

Submetido 08/04/2016 - Aceito 02/02/2017

DOI: $10.15628 /$ holos.2017.4393

\section{RESUMO}

É normal que educandos apresentem dificuldade na assimilação do conhecimento teórico da entomologia, já que exige alto grau de abstração. As atividades de campo são métodos utilizados para a redução deste impedimento, norteando uma aprendizagem significativa e amplificando o trabalho grupal. Sendo assim, este trabalho objetivou desenvolver a prática de coleta e catalogação de insetos para a confecção de coleções entomológicas nas Escolas Estaduais de Ensino Profissionalizante dos municípios de Guaiúba e Viçosa do Ceará. Para o desenvolvimento desse trabalho, os alunos coletaram insetos nas escolas e suas periferias, os exemplares capturados eram catalogados e inseridos em caixas entomológicas. Na execução das atividades pôde-se observar um grande comprometimento $\mathrm{e}$
\end{abstract}

interesse dos educandos, principalmente por se tratar de uma atividade diferenciada (fora da sala de aula); também, nas diversas fases da atividade, foi observado nitidamente o intercâmbio de conhecimentos, configurando-se assim, uma aprendizagem cooperativa, constatada por observações in loco. Ao final da disciplina foi constatado que nenhum educando necessitou de processo de intervenção educacional, uma vez que a análise das avaliações escritas e não escritas apresentou uma real assimilação do conhecimento. Nesse sentido, a confecção de coleção entomológica mostrou-se um recurso significativamente eficiente no ensino da disciplina de Entomologia Agrícola e Combate a Pragas e Doenças.

PALAVRAS-CHAVE: Coleção Entomológica, Estratégias de Aprendizagem, Métodos de Ensino, Ensino Médio.

\section{CONSTRUCTION OF ENTOMOLOGICAL BOXES AS A TOOL FOR TEACHING- LEARNING OF AGRARIAN TECHNICAL COURSES}

\begin{abstract}
It is normal that students have difficulty in the assimilation of theoretical knowledge of entomology, since it demands a high level of abstraction. Field activities are methods used to reduce this impediment, guiding significant learning and amplifying teamwork. Thus, this study aimed to develop the practice of collecting and cataloging insects for making entomological collections in the State Schools of Vocational Education of the municipalities of Guaiúba and Viçosa do Ceará. The development of this work, the students collected insects in the schools and their peripheries, the specimens captured were cataloged and inserted in entomological boxes. In executing of the
\end{abstract}

activities could be observed a great engagement and interest of the students, mainly because it is a different activity (outside the classroom); also, at different stages of activity was clearly observed the exchange of knowledge, setting up a cooperative learning, verified by on-site observations. At the end of the course it was found that no student required educational intervention process, once the analysis of the written evaluations and unwritten showed a real assimilation of knowledge. In this sense, the production of entomological collection was shown to be a significantly effective resource in teaching the discipline of Agricultural Entomology and Pests Combat and Diseases.

KEY WORDS: Entomological Collection, Learning Strategies, Teaching Methods, High School. 


\section{INTRODUÇÃO}

É de conhecimento dos professores de ciências o fato de a experimentação despertar um forte interesse entre os alunos em diversos níveis de escolarização. Nesse sentido, essas atividades práticas atribuem um caráter motivador, lúdico, essencialmente vinculado aos sentidos, que, de algum modo, possibilita o aumento da capacidade de aprendizado, pois funciona como um meio de envolver o aluno nos temas que estão em pauta (Giordan, 1999). Para tanto, cabe ao professor proporcionar ambiente de mediações ou até mesmo de "facilitações" da ação do aluno, no sentido de garantir a interação entre o sujeito e o ambiente da sala de aula, do qual fazem parte seus colegas e os conteúdos escolares (Delizoicov, Angotti e Pernambuco, 2011).

O uso de atividades práticas torna-se uma ferramenta pedagógica importante que traz expressivas contribuições ao processo de ensino-aprendizagem no ensino de Ciências e Biologia, contribuindo para o desenvolvimento social e cognitivo dos alunos. Dessa forma, o uso dessas metodologias de experimentação permite aos alunos ampla visualização das questões cotidianas, favorece o caráter investigativo e propicia maior interesse dos alunos no assunto abordado (Goldbach, Papoula, Sardinha, Dyrarz e Capilé, 2009).

Essa forma de construção do conhecimento é uma visão de aprendizagem que leva em conta a cognição situada. Nessa abordagem, o conhecimento surge na interação entre os aprendizes e em um determinado entorno espaço-temporal. Desse modo, vai ao encontro da pedagogia de Paulo Freire que defende que a situacionalidade é um pré-requisito para a compreensão da realidade por parte daquele que quer intervir e não ser um mero espectador/reprodutor na sociedade (Freire, 1985).

A aprendizagem como cognição situada possibilita enxergar o processo de ensino/aprendizagem como algo que emana de uma situação autêntica de interação; por isso, nessa abordagem, é rejeitada a produção de conhecimento desvinculada de situações autênticas. No caso do ensino de Ciências, evita-se praticar exercícios escolares desgarrados de eventos reais. Melhor do que ofertar pacotes de informações pré-fabricadas e descontextualizadas aos alunos, Costa (2010) sugere que a uma boa maneira de se construir um aprendizado significativo se dá na tentativa de despertar os interesses dos alunos, de sensibilizá-los para o que será discutido e possibilitar oportunidades para que os estudantes se apropriem do "conhecimento necessário para dar resposta às suas demandas".

Nesse sentido, o processo educativo requer uma aprendizagem significativa que atenda a aprendizagem de conceitos, de modo que a exposição de significados contextuais apresentados aos alunos pelos professores permita aos discentes compreendê-los, ancorando-se em conceitos já estabelecidos cognitivamente e possam posteriormente compartilhá-los (Albuquerque, Milléo, Lima e Barbola et al., 2014). Com isso em vista, o que se pretende com a presente proposta de uma metodologia alternativa é que haja uma vivência prática dos alunos com as temáticas abordadas, de modo que suas próprias concepções e dúvidas sejam respondidas por si mesmas, utilizando do conhecimento científico para repensar questões relacionadas ao senso comum (Lima, Ayub, Morales e Lorencini-Júnior, 2012).

A aplicação de atividades deve ser ancorada em objetivos delineados, de forma articulada e fundamentada, possibilitando ao educando a oportunidade de estabelecer conexões necessárias para a compreensão dos conceitos aprendidos. No ensino de disciplinas técnicas, como a Entomologia Agrícola, são variados os conteúdos que podem ser ministrados por meio do 
uso de atividades experimentais, necessitando, em alguns momentos, de material didático suplementar (Albuquerque et al., 2014).

A entomologia é um campo da biologia que estuda os insetos e sua relação com o meio ambiente (Brasil, 2003). Dessa forma, na tentativa de tornar este estudo mais significativo, normalmente são confeccionadas caixas com coleções entomológicas, armazenando de forma organizada os exemplares (espécimes) de insetos previamente capturados e preservados para estudos científicos. Estas coleções são importantes registros da existência de espécies no tempo e no espaço, sendo uma importante ferramenta para estudos ecológicos de solução de problemas nas áreas de agropecuária, saúde e zootecnia, além de auxiliar na educação ambiental de jovens (Jurberg, 2005).

Segundo Costa, Ide, Rosado-Neto, Galileo, Fonseca, Valente e Monné (2000), as coleções entomológicas são repositórios dos espécimes-tipo essenciais para a identificação precisa de espécies; ao mesmo tempo, são documentos da fauna de áreas perturbadas, ou em vias de desaparecimento, indispensáveis nas pesquisas em sistemática, evolução e biodiversidade. Em resumo, as coleções são acervos insubstituíveis, cuja preservação não pode ser descuidada nem interrompida.

A coleta de insetos é o primeiro passo na estruturação e preparação de uma coleção entomológica, seja ela temática ou não (Chiesa, Modena e Diel, 2013). As coletas permitem realizar coleções didáticas, úteis para o ensino formal de ciências, além de ser um importante acervo para a conservação e entendimento da biodiversidade. Dessa forma, coletar, montar e preservar insetos é uma excelente maneira de aprender sobre eles (Azevedo, Figueiró, Alves, Vieira e Senna, 2012).

Segundo Santos e Souto (2011), a montagem de coleções entomológicas em escolas ampara a aprendizagem dos alunos, fazendo com que derrubem mitos e construam uma visão crítica sobre o tema para uma melhor acomodação do conhecimento. Isto se dá nas atividades externas, como a coleta de insetos; e, nas atividades internas, como a confecção de chaves entomológicas, que consiste em um sistema utilizado na classificação dos seres vivos, facilitando a organização da informação e, neste caso, o descobrimento da ordem que pertence determinado inseto.

$\mathrm{Na}$ determinação dos insetos, a chave de identificação ou chave dicotômica contém descrições sistemáticas possíveis de identificar e caracterizar cada organismo, pois descrevem com exatidão as espécies ou espécimes analisados, além de comprovar e registrar suas características e determinar sua classificação taxonômica (Silva, Barbosa e Albuquerque, 2010).

Existem diferentes modelos de chaves de identificação, a saber: as chaves pictóricas, caraterizadas por apresentar imagens anexas que ilustram o caráter taxonômico; as chaves dicotômicas, destinada à identificação em tomada de decisões entre duplas opções apresentadas e as chaves interativas, que utilizam uma matriz de dados de espécies versus combinações de caracteres (Fujihara, 2008). Estudar os insetos no âmbito formal, de modo a demonstrar tais aspectos e relações com o ser humano, é de grande relevância, principalmente em cursos técnicos voltados para a agricultura (Albuquerque et al., 2014).

Aliado a isso, as atividades práticas contribuem para o interesse e a aprendizagem em Ciências (Andrade e Massabni, 2011), principalmente nas temáticas de cunho científico, cuja metodologia de trabalho está inserida na pedagogia das escolas de ensino profissional. Aulas no ensino de ciências desenvolvidas em ambientes naturais têm se apresentado como eficazes, pois oportunizam aos alunos envolvimento nas atividades educativas e constituem um instrumento 
importante de superação da fragmentação do conhecimento (Seniciato e Cavassan, 2004). Contudo, fatores limitantes, como falta de equipamentos e instalações adequadas, impedem o exercício de atividades práticas ou experimentais pelos professores (Goldbach et al., 2009).

Considerando a necessidade de realizar atividades práticas que despertem o interesse dos alunos, as limitações orçamentárias que a escola tem e a ausência de equipamentos próprios às aulas técnicas, esse trabalho visou construir caixas entomológicas como alternativa didática às aulas das disciplinas de Entomologia Agrícola e Combate a Pragas e Doenças, do curso Técnico em Agropecuária e do curso Técnico em Fruticultura, bem como em disciplinas afins; e avaliar a eficiência dessa abordagem didática na construção do conhecimento dos alunos envolvidos.

\section{METODOLOGIA}

O estudo foi desenvolvido com 40 alunos dos 2 ㅇ e 3 o anos do curso Técnico em Agropecuária da Escola Estadual de Educação Profissional José Ivanilton Nocrato, e do 20 ano do curso Técnico em Fruticultura da Escola José Victor Fontenelle Filho, situadas, respectivamente, nas cidades de Guaiúba e Viçosa do Ceará, Estado do Ceará. Para elaboração da presente pesquisa, classificada como pesquisa descritiva quanto os seus objetivos (Gil, 2002), foi utilizado o método da pesquisa-ação para coleta de dados.

As atividades realizadas tiveram duração correspondente a uma aula de 45 minutos e três aulas de 90 minutos, monitorada por dois docentes. Antes de iniciar as aulas práticas, os discentes tiveram uma aula teórica sobre como coletar, sacrificar e armazenar os insetos. Todos os alunos das respectivas turmas participaram da aula prática, coletando os insetos nas matas que circundam ambas as escolas com auxílio de rede entomológica e captura direta, além de conduzirem um recipiente para acondicionar os insetos coletados (Figura 1). Após a coleta de cada inseto, os espécimes foram imediatamente sacrificados em câmara mortífera contendo acetato de etila e transferidos para frascos plásticos individuais devidamente etiquetados com as seguintes informações: local da coleta, coletor, data e hora (Figura 1). 

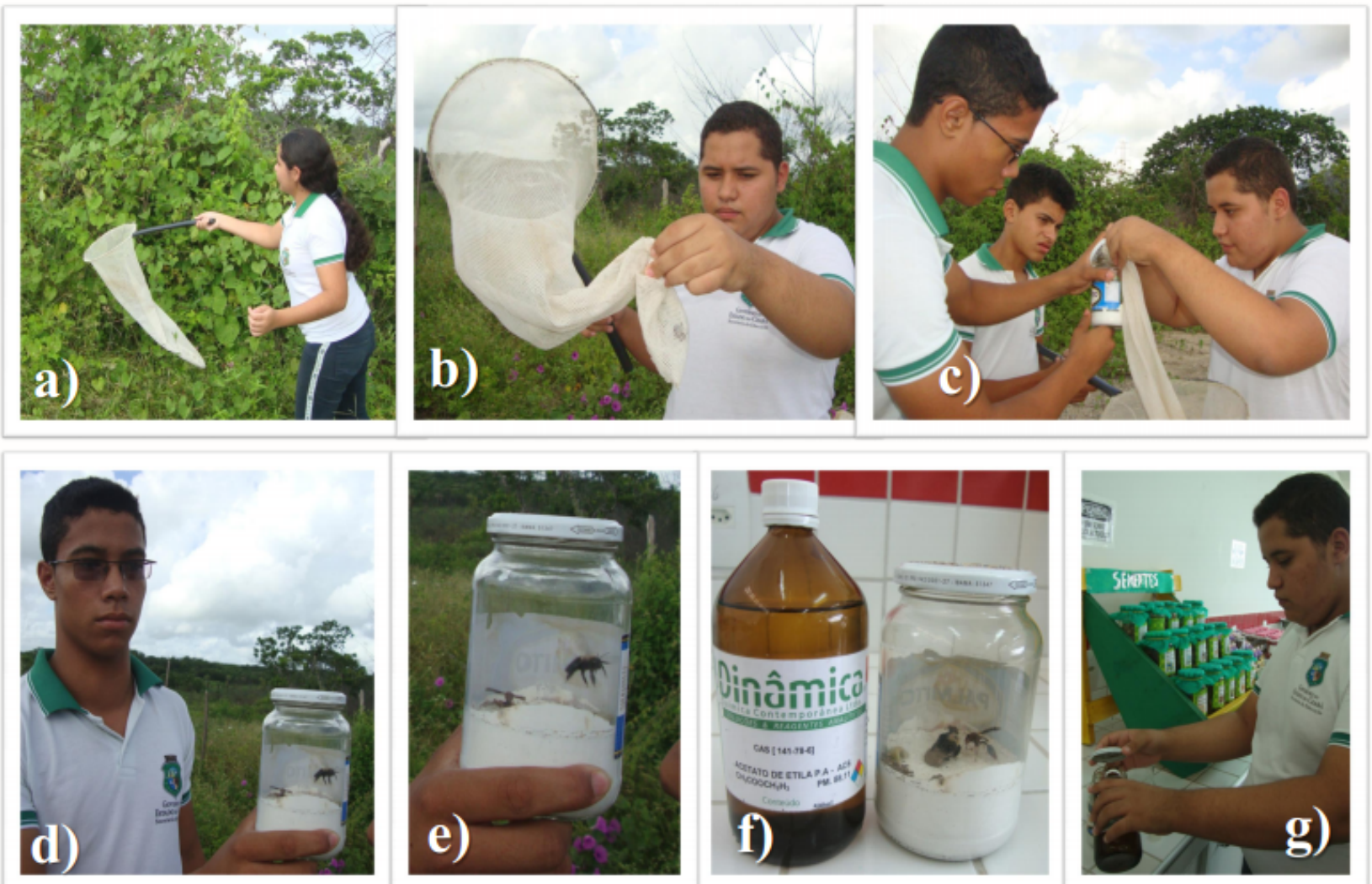

Figura 1: a) Aluna coletando inseto com assistência de rede entomológica, na mata onde circunda a escola; b) Inseto capturado no interior da rede entomológica; c) Inseto sendo transferido para câmara mortífera contendo acetato de etila em seu interior; d) e e) Inseto no interior da câmara mortífera; f) Frasco de acetato de etila junto à câmara mortífera; g) Aluno adicionando acetato de etila no interior da câmara mortífera.

Após 45 minutos de coleta ao redor da mata das escolas, os alunos foram levados ao Laboratório de Biologia. Quando os insetos ainda se encontravam vivos, após esse período, era adicionado mais acetato de etila à câmara mortífera para que o mesmo tivesse mais contato com o produto e fosse sacrificado (Figura 1). Após serem sacrificados, os insetos eram montados em alfinetes entomológicos com subsídio de um suporte de isopor e colocados em estufa artesanal, confeccionada pelos próprios alunos, a uma temperatura média de $40^{\circ} \mathrm{C}$, por um período que variava de 24 a 48 horas, dependendo do tamanho da espécie (Figura 2). Posterior a isto, os espécimes eram devidamente etiquetados e identificados em nível de ordem com auxílio de chave de identificação simplificada. A identificação taxonômica realizada pelos educandos por meio de Chaves Entomológica em nível de espécie será realizada a posteriori.
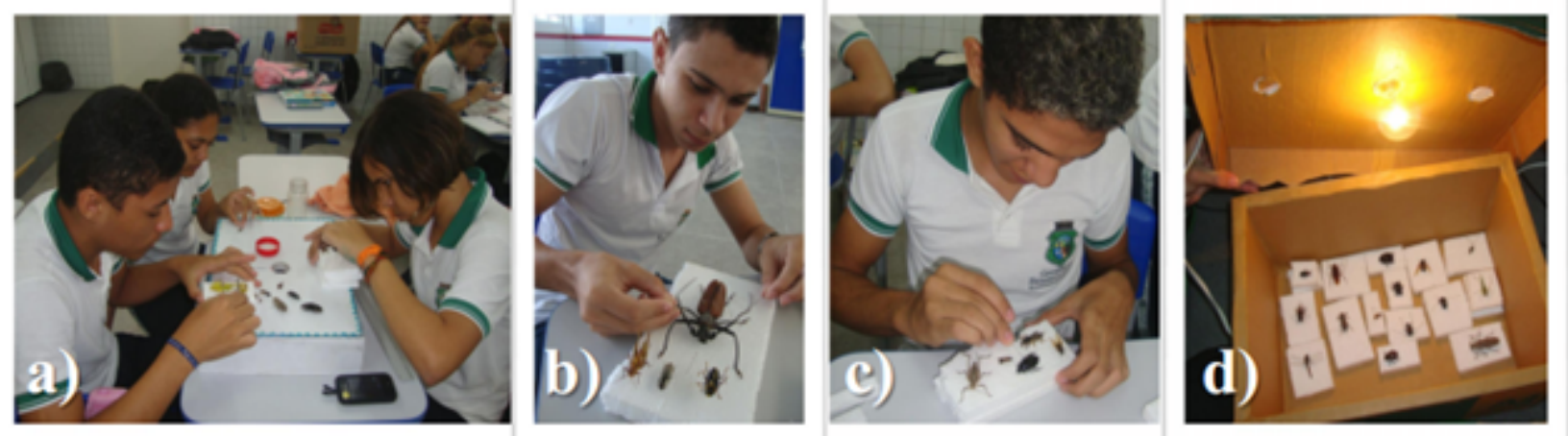

Figura 2: a), b) e c) Alunos montando insetos em alfinete entomológico no suporte de isopor; d) Insetos secando em estufa artesanal confeccionada pelos alunos. 
A estufa para secagem dos insetos foi confeccionada, de forma artesanal, pelos alunos, utilizando materiais de baixo custo, como caixas de papelão revestidas com isopor nas paredes laterais e fundo, posteriormente coberta com fita adesiva. Por fim, foi introduzida uma ligação elétrica de lâmpada incandescente através de interruptor simples que foi acoplada na tampa da estufa. Para esta atividade, houve uma parceria com o professor de física da Escola Estadual de Educação Profissional, José Ivanilton Nocrato, de Guiaiúba, que instruiu como os alunos deveriam realizar a atividade quando ministrou o conteúdo de eletricidade.

As caixas entomológicas foram adquiridas em uma marcenaria localizada no município de Guaiúba/Ceará, possuindo as medidas de $60 \times 60 \times 6 \mathrm{~cm}$, e tampa de vidro para visualização da coleção entomológica. Em seguida, os alunos preparam-nas para acondicionar os insetos, colocando isopor no fundo da caixa e, por fim, revestindo com E.V.A. (espuma vinílica acetinada) amarelo.

\section{RESULTADOS E DISCUSSÃO}

Como objetivo tangível do projeto, foram confeccionadas duas caixas entomológicas de madeira com os insetos mais comumente encontrados na região de Guaiúba/Ceará, e uma com os insetos encontrados na região de Viçosa do Ceará/Ceará, para atender os objetivos não tangíveis que foram maior participação dos alunos nas atividades, cooperação entre os alunos e melhor assimilação do conteúdo.

Essas caixas serviram e servirão para facilitar o ensino de anatomia dos insetos, hábitos alimentares através dos aparelhos bocais, locomoção e identificação de potenciais pragas de culturas agrícolas. Segundo Santos e Souto (2011), a montagem de coleções entomológicas em escolas auxilia no aprendizado dos alunos, fazendo com que derrubem mitos e construam uma visão crítica sobre o tema.

A coleção ficará guardada no Laboratório de Biologia das escolas e servirá como um recurso didático a ser utilizado tanto em disciplinas de base técnica dos cursos Técnicos em Agropecuária e em Fruticultura para as respectivas escolas, como em disciplinas da base comum, como Biologia (Figura 3).

De acordo com Matos, Oliveira, Santos e Ferraz (2009), o uso de metodologias alternativas para o ensino deve ser estimulado nas instituições como uma forma de possibilitar e incentivar a participação dos alunos no processo de aprendizagem, bem como promover a integração entre conteúdos e desenvolvimento de aulas práticas, intercâmbio entre os alunos através da troca de conhecimento, criatividade e espírito de equipe, além da reutilização do material produzido em outras atividades como oficinas para escolas, empréstimos para feiras cientificas, dentre outros.

Conforme a aluna Ana Paula, essas atividades foram relevantes por fazer com que o aluno saia da "monotonia" da sala de aula. A aluna também relatou que essa prática mudou sua forma de pensar e entender os insetos. Quando os educandos realizam práticas externas a sala de aula, isso desperta neles mais curiosidade e um maior senso de pesquisa. $\mathrm{O}$ aluno João afirmou que as atividades práticas foram muito divertidas e o ajudaram a interagir com o restante da turma. Outros alunos também relataram que anteriormente tinham receio ou até medo de tocar em insetos; contudo, durante as atividades, eles foram percebendo que com a técnica correta não 
havia problema e nem perigo. Para transpor essa barreira do medo, muitos alunos necessitaram do apoio e do incentivo dos demais colegas para realizar a coleta e outras atividades.

Outra abordagem interessante, que se pode destacar, foi à relação interdisciplinar da Biologia com a Física na confecção da estufa para secagem dos insetos, na exposição do professor com relação aos conceitos de calorimetria, o porquê da estufa ser de isopor com uma lâmpada incandescente, para a geração e conservação de calor. Essa interdisciplinaridade ficou mais nítida no comentário de um aluno quando este relatou que nunca pensaria que poderia utilizar conceitos físicos de calorimetria para trabalhar com insetos.
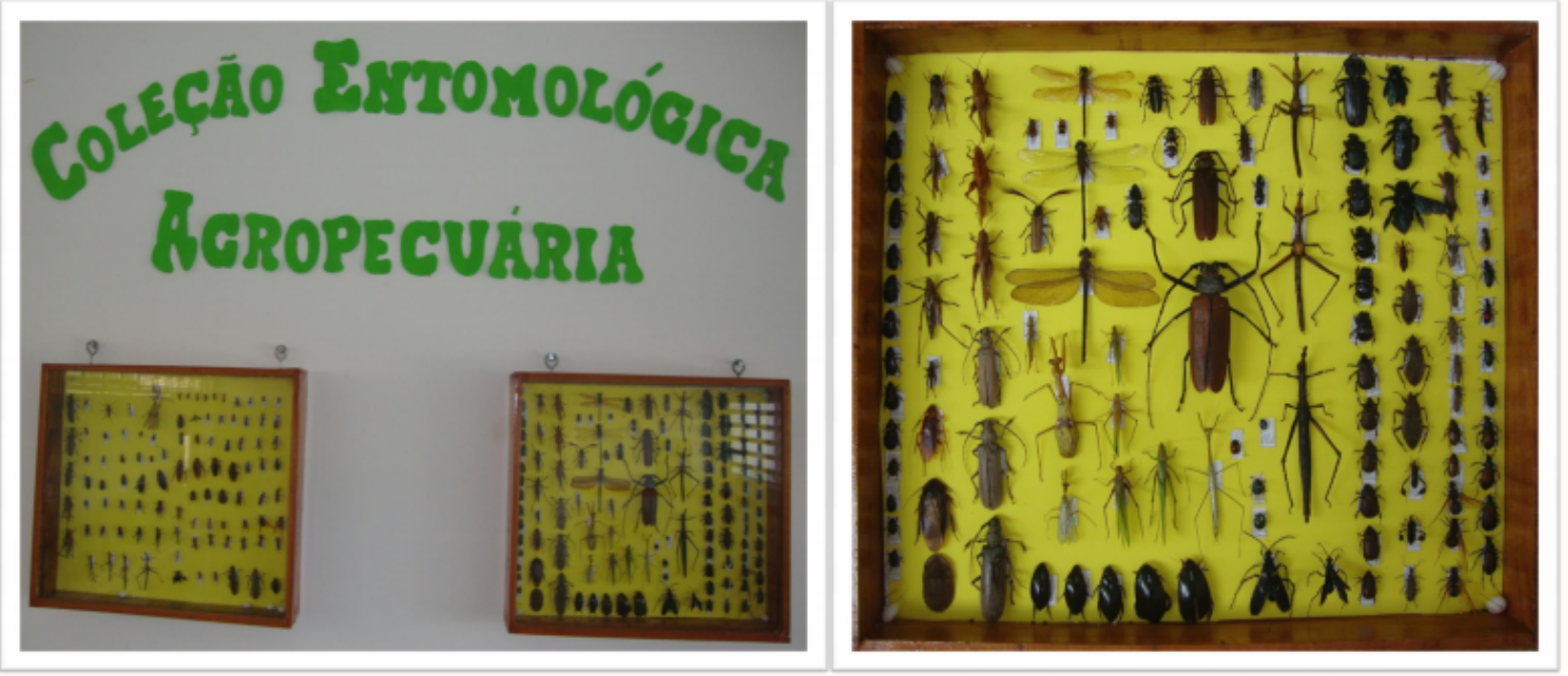

Figura 3: Coleção entomológica na parede do Laboratório de Biologia, evidenciando a diversidade de insetos coletados pelos alunos.

Após todo o conteúdo ser ministrado e a coleção entomológica confeccionada, os alunos fizeram avaliações teóricas e práticas sobre o referido tema e os resultados foram satisfatórios, tanto na Escola Estadual de Educação Profissional José Ivanilton Nocrato, em Guaiúba, quanto na Escola José Victor Fontenelle Filho, em Viçosa do Ceará. Como resultado, nenhum aluno necessitou passar pelo processo de intervenção educacional em ambas as escolas. Esses processos de intervenções consistem em atividades que fazem parte de uma metodologia para a recuperação de conhecimentos não assimilados pelos educandos durante o processo educacional convencional, fazendo parte desde aulas extras específicas, trabalhos extraclasses e acompanhamento individual de cada aluno visando a apropriação do conhecimento por parte deste. A ausência dessas intervenções pedagógicas nas disciplinas ministradas evidencia que a prática situada dos conhecimentos não apenas teve aceitação por parte dos alunos, mas, sobretudo, indica sua eficácia ao ensino-aprendizagem.

Na Tabela 1 é possível observar que a média geral das disciplinas que se utilizaram do insetário foi maior do que as disciplinas que foram ministradas apenas teoricamente, sem a possibilidade de atividades práticas significativas. Outro dado relevante foi a moda, ou seja, os valores que mais apareceram entre as notas dos educandos, nas quais as disciplinas de Combate a Pragas e Doenças e Entomologia Agrícola obtiveram os mesmos valores $(7,5)$, enquanto que a outra disciplina obteve uma moda de 6,5, o que indica, numericamente, que os alunos das disciplinas que se utilizaram do insetário, obtiveram notas maiores do que as notas da disciplina teórica. 
Tabela 1: Comparativo entre dados das disciplinas que se utilizaram do insetário como prática e das que foram apenas teóricas.

\begin{tabular}{cccc}
\hline & $\begin{array}{c}\text { Combate a } \\
\text { Pragas e } \\
\text { Doenças }\end{array}$ & $\begin{array}{c}\text { Entomologia } \\
\text { Agrícola }\end{array}$ & $\begin{array}{c}\text { Disciplinas que não } \\
\text { foram realizadas } \\
\text { práticas }\end{array}$ \\
\hline Média & 7,10 & 7,40 & 6,60 \\
Máximo & 7,50 & 8,00 & 8,50 \\
Mínimo & 6,50 & 6,50 & 4,50 \\
Moda & 7,50 & 7,50 & 6,50 \\
\hline
\end{tabular}

Outro benefício encontrado nesse processo de coleta e catalogação dos espécimes foi a troca de conhecimentos entre os educandos, o que segundo Barbosa e Jófilli (2004) é o principio básico fundador de uma aprendizagem cooperativa.

Segundo Zompero e Laburú (2010) e Barbosa e Jófili (2004) a união desses dois pontos em uma investigação a campo (aula de campo) com o auxílio e colaboração entre colegas é o princípio norteador de uma aprendizagem cooperativa e significativa. Facilitando a assimilação do conhecimento por parte dos educandos, esse modelo de aprendizagem vem tendo mais foco a cada dia por apresentar uma troca de conhecimento entre os participantes. Quando o educando por si só realiza uma atividade, a qual finaliza com um material concreto que ele possa ver e tocar com ajuda do outro, ele pode ver de forma não abstrata o conhecimento construído por ele.

\section{CONCLUSÃO}

A coleção entomológica mostrou-se um importante recurso didático para o ensino da disciplina de Entomologia Agrícola e Combate a Pragas e Doenças, pois, além de constituir um material de baixo custo, teve a potencialidade de tornar as aulas mais atraentes aos educandos e, assim, tornar o aprendizado mais eficiente.

A confeç̧ão de uma coleção entomológica apresentou-se como uma eficiente estratégia de aprendizagem nas escolas profissionalizantes, permitindo melhor aproveitamento das aulas por meio do contato teórico-prático com o conteúdo abordado como também despertando a percepção entomológica dos escolares envolvidos na atividade. Ademais, uma coleção entomológica pode ser inserida em diversas outras atividades educacionais da escola, podendo ser um importante recurso didático-pedagógico nas aulas de Biologia, Geografia e Física.

\section{REFERÊNCIAS}

Albuquerque, F. P., Milléo, J., Lima, J. M. M., Barbola, I. F. (2014). Entomologia no ensino médio técnico agrícola: uma proposta de trabalho. Revista Eletrônica de Educação, 8(3), 251-265.

Andrade, M. L. F., Massabni, V. G. (2011). O desenvolvimento de atividades práticas na escola: um desafio para os professores de ciências. Ciência e Educação, 17(4), 835-854.

Azevedo, H. J. C. C., Figueiró, R., Alves, D. R., Vieira, V., Senna, A. R. (2012). O uso de coleções zoológicas como ferramenta didática no ensino superior: um relato de caso. Revista Práxis, 4(7), 43-48. 
Barbosa, R. M. N., Jofili, Z. M. S. (2004). Aprendizagem cooperativa e ensino de química: parceria que dá certo. Ciência e Educação, 10(1), 55-61.

Brasil. (2003). Profissionalização de auxiliares de enfermagem: cadernos do aluno. (2a ed.). Rio de Janeiro: Fiocruz.

Costa, C., Ide, S., Rosado-Neto, G. H., Galileo, M. H. M., Fonseca, C. R. V., Valente, R. M., Monné, M. A. (2000). Diagnóstico del conocimiento de las principales coleciones brasileñas de coleóptera. In Martín-Piera, F., Morrone, J. J., Melic, A. (Coords.), Proyecto para Iberoamérica de Entomología Sistemática (p. 115-136). Zaragoza: Sociedad Entomológica Aragonesa.

Costa, M. H. A. (2010). Linguagem como interlocução e aprendizagem como cognição situada. Linguagem em Foco, 2(2), 151-167.

Chiesa, A. F. S., Modena, G., Diel, M. (2013). Coleção entomológica. In Mostra Nacional De Iniciação Científica e Tecnológica Interdisciplinar (p. 01-05). Camboriú: Instituto Federal Catarinense.

Delizoicov, D., Angotti, J. A., Pernambuco, M. M. (2011). Ensino de ciências: fundamentos e métodos. São Paulo: Editora Cortez.

Freire, P. (1985). Educação e mudança. (9a ed.) São Paulo: Paz e Terra.

Fujihara, R. T. (2008). Chave pictórica de identificação de famílias de insetos-praga agrícolas. (Dissertação. Universidade Estadual Paulista “Júlio de Mesquita Filho", Botucatu).

Gil, A. C. (2002). Como elaborar projetos de pesquisa. (4a ed.). São Paulo: Atlas.

Giordan, M. (1999). O papel da experimentação no ensino de ciências. Química Nova na Escola, 10(10), 43-49.

Goldbach, T., Papoula, N. R. P., Sardinha, R. C., Dysarz, F. P., Capilé, B. (2009). Atividades práticas em livros didáticos atuais de biologia: investigações e reflexões. Revista Perspectivas da Ciência e Tecnologia, 1(1), 64-74.

Jurberg, C. (2005). Bibliografia de Jocélia Grazia. Entomología y Vectores, 12(1), 01-18.

Lima, J. M. M., Ayub, C. L. S., Morales, A. G., Lorencini-Júnior, A. (2012). Aproximação entre a teoria histórico-crítica e a aprendizagem significativa: uma prática pedagógica para o ensino de biologia. Aprendizagem Significativa em Revista, 2(2), 54-64.

Matos, C. H. C., Oliveira, C. R. F., Santos, P. M. F., Ferraz, C. S. (2009). Utilização de modelos didáticos no ensino de entomologia. Revista de Biologia e Ciências da Terra, 9(1), 19-23.

Santos, D. C. J., Souto, L. S. (2011). Coleção entomológica como ferramenta facilitadora para a aprendizagem de ciências no ensino fundamental. Scientia Plena, 7(5), 01-08. 
Silva, M. A., Barbosa, J. S., Albuquerque, H. N. (2010). Levantamento das plantas espontâneas e suas potencialidades fitoterapêuticas: um estudo no complexo Aluízio Campos, Campina Grande, PB. Revista Brasileira de Informações Científicas, 1(1), 52-66.

Seniciato, T., Cavassan, O. (2004). Aulas de campo em ambientes naturais e aprendizagem em ciências: um estudo com alunos do ensino fundamental. Ciências e Educação, 10(1), 133-147.

Zompero, A. F., Laburu, C. E. (2010). As atividades de investigação no Ensino de Ciências na perspectiva da teoria da Aprendizagem Significativa. Revista Electrónica de Investigación en Educación en Ciencias, 5(2), 12-19. 